\title{
(A)bridging the Gap - A study of the norms and laws in the intralingual translation of the novel And Then There Were None by Agatha Christie
}

\author{
Manuel Moreno Tovar ${ }^{1}$. \\ University of Tartu \\ Vladimir Admoni Doctoral Room, Jakobi 2, 51003 Tartu $\cdot$ Estonia
}

ABSTRACT

In the last decade, intralingual translation has started to gain momentum amongst a number of translation academics. Nevertheless, some types of intralingual translation remain largely undiscovered, such as the process of abridgement in the production of simplified versions of classic literary works (i.e. graded readers). This article subjects three chapters of the abridged version of And Then There Were None by Agatha Christie to qualitative analysis using Descriptive Translation Studies theory. The aim is to contribute to bridging a research gap in Translation Studies by examining the norms and laws governing the process of abridgement. Translation norms and laws are detected by situating the source and the target texts in their respective socio-cultural backgrounds and by analysing translation shifts. Relevant shifts are identified by means of a check-list of features elaborated on the basis of theory on graded readers, which classifies them into lexical, structural and information shifts. The results of the analysis showcase the vast research potential of intralingual translation for language learning purposes.

Keywords: Intralingual translation, abridgement, graded readers, DTS, translation norms, translation laws, Agatha Christie, And Then There Were None

\section{Theoretical framework}

Intralingual translation is an under-researched area in Translation Studies that challenges the very foundations of the concept of translation, which is typically based on the notion of interlinguality. Its theoretical foundations can be traced back to Jakobson's tripartite definition of translation, where he described intralingual translation as "an interpretation of verbal signs by means of other signs of the same language" (1959,p. 114). This definition was complemented by the notions of interlingual translation or 'translation proper' and intersemiotic translation or 'transmutation'. Regrettably, four decades later the concept of 'translation' had only been used as a de facto synonym of 'translation proper', as Baker noted in her Encyclopedia of Translation Studies: "I know of no research that looks specifically at the phenomena of intralingual or intersemiotic translation" (1998, p. xvii).

Zethsen was one of the first translation academics to account for the other forms of translation in Beyond Translation Proper-Extending the Field of Translation Studies (2007). By the same token, Schmid claimed that Translation Studies needed to expand in order to include intralingual practices, e.g. reformulations of technical texts for a lay audience, popularisation of scientific texts and legal texts made more accessible to the public at large. He defended the need to recognise intralingual practices as rightful translation "in order to 
maintain coherence between the theories developed in Translation Studies and the translation practice they seek to explain" (2008, p. 20). In Intralingual Translation: An Attempt at Description, Zethsen identified the main parameters that instigate intralingual practices, i.e. knowledge, time, culture and space (2009, pp. 805-807).

Over the last few decades, a growing interest in expanding the concept of translation has resulted in an increased number of publications on intralingual translation. This turn has been witnessed by the International Workshop on Intralingual Translation held at Boğaziçi University in Istanbul in 2014 and the panel 'Intralingual translation - Breaking boundaries?' at the EST 2016 Congress at Aarhus University.

In spite of this increased interest, certain types of intralingual translation have only been superficially addressed. This is the case of the research topic of this article, i.e. the phenomenon of abridgement for language learning purposes. This occurs in the production of graded readers, which are defined by the Extensive Reading Foundation (a not-for-profit organisation that promotes extensive reading) as follows:

Graded Readers [...] are books (both fiction and non-fiction) written especially for language learners to build their reading speed and fluency and to give them chances to practice 'real' reading for pleasure. They are called 'graded' readers because they are written according to pedagogical syllabus which has increasing grades, or levels, of difficulty. They are graded through tight control of the plot, vocabulary, and grammar and judicious use of images (The Extensive Reading Foundation, 2011, p. 2).

When it comes to classifying graded readers, different taxonomies have been adopted by academics. Waring (2003, p. 2) mentions three main types of readers:

- Adapted readers in which the story is retold or simplified to improve the fluency and comprehensibility of the language learners. They are called 'adaptations'.

- Abridged readers, in which the main story remains unaltered, but simplifications take place in order to meet the grading criteria. They are called 'abridgements'.

- Original stories, which may be fictional and non-fictional (e.g. biographies and reports) and are called 'originals'.

In this article, the focus will lie on abridged graded readers. It must be stressed that the terms 'adapted' and 'abridged' are often used interchangeably and that some scholars such as Simensen (1987, p. 43) use 'adapted' as a superordinate term for the various kinds of modifications, including abridgement. However, here, the term 'abridged' has been preferred in order to distinguish these readers from non-abridged adaptations. Other frequently used terms include 'reduced', 'retold', 'rewritten' and 'simplified'.

Graded readers have two equally important purposes: to bring enjoyment and pleasure to the language learner, and to increase their language proficiency by reading extensively and individually (Bassett, 2011, p. 29). This methodology has been largely known in the discipline of Second Language Acquisition as 'extensive reading', but it is also referred to as 'individualised reading' and 'self-selected reading' (The Extensive Reading Foundation, 2011, p. 3).

In extensive reading, learners are encouraged to choose what they want to read and to do it as much as possible (Day, 2011, p. 11). For this reason, publishers have developed a wide range of graded reader series covering different topics and levels. The required degree of simplification or 'control' in a graded reader will largely depend on the target learners' proficiency. Beginning and intermediate learners will need to have their reading material extensively modified, something that advanced readers may not require (Waring, 2003, p. 12). The 
research conducted by Hedge (1985) on the production of graded readers shows that control is applied at three levels: lexical and structural control (both of which Simensen categorises as 'control of language') and information control. These three levels of control, as characterised below, will serve as structural basis for this project's analysis.

\subsection{Lexical control}

According to Waring, lexical control involves "the use of easier or already known words instead of more difficult and less useful ones. This can take place not only at the individual word level but also at the phrase level and will probably involve a change in the collocational and colligational relationships" (2003, p. 12).

Lexical control is usually applied by means of a lexical syllabus, i.e. a list of headwords that learners are expected to know at each level. Simensen's research (1987, pp. 50-52) shows that graded reader authors are encouraged to be careful with the overuse of figurative language (idiom, simile and metaphor). Similarly, the use of colloquialisms, archaisms and other forms of non-standard language is discouraged by publishers.

\subsection{Structural control}

Structural control may be exercised by means of a grading scheme that follows a gradual order of grammatical and syntactical structures (Hedge, 1985, p. 10). Usually, each level keeps pace with the grammar progression in its correspondent textbook (Bassett, 2011, pp. 23-24). Graded reader authors are reportedly encouraged to avoid or to be careful with the following structural elements (Waring, 2003, p. 10; Simensen, 1987, pp. 50-52):

- anaphora (the way in which words such as pronouns substitute for and refer back to noun phrases, which are known as antecedents),

- cataphora (forward referencing),

- exophora (references to elements that are not in the text),

- elliptical constructions (e.g. deletion of relative pronouns, subjects, the word 'that' after 'say' or 'think' and punctuation in coordinate or subordinate clauses), and

- difficult constructions (e.g. lengthy noun clauses, subclauses and relative clauses as subjects, contractions, inversions, indirect speech and participle phrases).

\subsection{Information control}

Information control fulfils two main functions: to reduce the length of the text and to make it easier for the readership to 'digest' the meaning (Leow, 1997). However, graded reader authors must keep in mind the amount of simplification applied in order to preserve a compelling story. Simensen (1987, p. 47) calls this 'avoiding density of information', i.e. not making the information in the abridged text more condensed than in the original. She lists some of the publishers' recommendations in terms of information control (1987, pp. 46-47):

- Cutting out all the 'marginal', 'peripheral', or 'irrelevant' information. Some publishers recommend omitting subplots which are not vital to the main plot, as well as minor or confusing characters. 
- Deleting unnecessary descriptive passages. If a descriptive passage is necessary to set a mood for a character, it is better to directly state the mood. It is important to keep a balance between descriptive text, which is syntactically denser, and dialogue, which tends to be easier to process.

- Considering cultural and background differences between the original readership and the language learners. In some cases, it might be necessary to add preliminary notes to explain culture-specific differences (e.g. a list with the main characters or an introduction which sets the context).

\section{Research Methodology}

This article has adopted a descriptive approach based on the three-phase methodology developed by Toury (1995) and summarised by Munday (2008, p. 111) as follows:

- Situate the text within the target culture system, looking at its significance or acceptability.

- Compare the ST (source text) and the TT (target text) for shifts, identifying relationships between 'coupled pairs' of ST and TT segments.

- Attempt generalisations, reconstructing the process of translation for this ST-TT pair.

\section{Contextualisation ${ }^{2}$}

Listed as the world's best-selling mystery and the seventh best-selling title of all time, And Then There Were None is considered to be Agatha Christie's masterpiece. It has been repeatedly adapted for theatre, television, radio and cinema, with new versions coming out every year, although sometimes with variations in the original setting or in the ending. Board games, video games and graphic novels inspired by it have also been released.

In 2011, Pearson published the abridged version of And Then There Were None for EFL (English as a Foreign Language) learners as a part of the series Pearson English Active Readers. Written in British English by Izabella Hearn, this reader belongs to the Level 3 of the series (pre-intermediate) and has 1200 headwords, which roughly corresponds to an A2 in the Common European Framework of Reference for Languages. It includes a CD and has a length of 80 pages and 18,683 words, excluding activities.

\section{Analysis}

This section carries out a descriptive analysis of a representative number of translation shifts ${ }^{3}$ from the research corpus $^{4}$. The selection of relevant shifts follows a 'repertory of features' approach, i.e. it is based on a check-list of elements to be examined (Munday, 2008, p. 122). This check-list consists of the elements that are subject to

2 As Munday points out, the status of the ST and the promotion of translation in its own culture may also influence the decision to translate it and the strategies employed (2008, p. 115). For this reason, the socio-cultural context of both texts has been examined.

3 The shifts are presented in two-column tables, in which column one indicates the number of the occurrence, column two contains the ST segment(s) and column three, the TT segment(s).

4 Due to the large size of the data, the research corpus has been restricted to the first three chapters of the novel, which were deemed to yield sufficient material. 
control in the production of graded readers as outlined by Hedge (1985), Simensen (1987) and Waring (2003). The analysis is structured in accordance with the three levels of control described in the theoretical framework, i.e. lexical, structural and information.

\subsection{Lexical level}

Translation shifts occurring at the lexical level involve the substitution of difficult words and phrases that might not be known by the target readership with more common choices. For instance, in Table 1, the word 'gull', which might be unfamiliar for the readership of the graded reader, has been replaced by its superordinate term 'bird'.

\begin{tabular}{lll}
\hline 1 & $\begin{array}{l}\text { Smelly sort of rock covered with gulls - } \\
\text { stood about a mile from the coast. }\end{array}$ & $\begin{array}{l}\text { Just a rock, really, covered in birds - about a } \\
\text { mile from the coast. }\end{array}$ \\
\hline
\end{tabular}

Table 1

In the TT, lexical control is applied through a list of 1,200 headwords corresponding to the Level 3 of the series Pearson English Active Readers. Unfortunately, this headword list is not available at the end of the TT, nor is a list of the 'additional' words related to the topic of crime or murder. However, some of the headwords can be guessed from the examples. In the previous segment, it can be assumed that 'smelly' is not on the headword list, whereas 'rock' and 'coast' are probably included. Interestingly enough, the word 'mile', which could be susceptible to experiencing a shift in an interlingual translation due to different systems of measurements, is maintained in the TT.

Further examples of lexical shifts in the research corpus include figurative language (idioms, metaphor and simile) and non-standard language (archaisms, dialect and colloquialisms).

\subsubsection{Figurative language}

\section{Idioms}

The translation of idioms and fixed expressions is a much-discussed subject in Translation Studies. Here, the word 'idiom' will be used as an umbrella term to encompass phrasal compounds (e.g. 'red herring'), proverbs (e.g. 'there is a fly in the ointment') and idioms proper (e.g. 'to roll in money'). The table below comprehends a non-exhaustive list of idioms in the corpus, including an extra column with the idiom for easier identification.

\begin{tabular}{|c|c|c|c|}
\hline 2 & $\begin{array}{l}\text { To surrender to } \\
\text { Cupid }\end{array}$ & $\begin{array}{l}\text { Mr Merryweather had had it whispered } \\
\text { to him that it had been bought for a } \\
\text { honeymoon-Young Lord L- had } \\
\text { surrendered to Cupid at last! }\end{array}$ & $\begin{array}{l}\text { Or did the mysterious 'Mr L' buy it } \\
\text { for his new wife? }\end{array}$ \\
\hline 3 & $\begin{array}{l}\text { There is a fly in the } \\
\text { ointment }\end{array}$ & $\begin{array}{l}\text { He thought: 'Soldier Island, eh? There's } \\
\text { a fly in the ointment.' }\end{array}$ & - \\
\hline 4 & $\begin{array}{l}\text { To be down to one's } \\
\text { last square meal }\end{array}$ & $\begin{array}{l}\text { A hundred guineas when he was } \\
\text { literally down to his last square meal! }\end{array}$ & $\begin{array}{l}\text { Lombard needed the money, but } \\
\text { asked for more information. }\end{array}$ \\
\hline 5 & To roll in money & These Owens must be rolling in money. & $\begin{array}{l}\text { These Owens were clearly very } \\
\text { rich! }\end{array}$ \\
\hline 6 & $\begin{array}{l}\text { To come out in the } \\
\text { open }\end{array}$ & Was he to come out in the open, or not? & Should he tell the true story or not? \\
\hline
\end{tabular}




\begin{tabular}{|c|c|c|c|}
\hline 7 & Take it or leave it & $\begin{array}{l}\text { 'Take it or leave it, Captain Lombard.' } \\
\text { He had said thoughtfully: 'A hundred } \\
\text { guineas, eh?' }\end{array}$ & $\begin{array}{l}\text { 'Here’s } £ 100 \text {. Take it or leave it, } \\
\text { Lombard,' were Isaac Morris’s } \\
\text { words a few weeks' earlier. }\end{array}$ \\
\hline 8 & Red herring & $\begin{array}{l}\text { Four little soldier boys going out to sea; } \\
\text { A red herring swallowed one and then } \\
\text { there were Three. }\end{array}$ & $\begin{array}{l}\text { Four little soldier boys were going } \\
\text { out to sea. A red herring ate one } \\
\text { and then there were three. } \\
\text { Footnote: red herring (n) } \\
\text { something that takes your thoughts } \\
\text { away from something important }\end{array}$ \\
\hline
\end{tabular}

Table 2

As it can be observed in the examples, different strategies have been adopted by Hearn. For instance, in segments 2 and 3, idioms have been omitted in the TT. This decision may have been triggered by the fact that the sentences containing the idioms were not essential for the plot. However, the most common strategy appears to be paraphrase or explicative translation, which can be found in segments 4 ('to need money'), 5 ('to be very rich') and 6 ('to tell the true story'), amongst others.

There are only two cases in which the idioms have been maintained: segment 7 ('take it or leave it') and segment 8 ('red herring'). Regarding the former idiom, it is possible that it was left 'untranslated' due to its transparency and to the literality of its meaning in this situation. The 'red herring' deserves special attention, since this expression is part of the nursery rhyme that defines the narrative structure of the novel. It is likely that this was the key factor in Hearn's decision to explain the meaning of this idiom in a footnote.

\section{Metaphor and simile}

Metaphor and simile are two of the most frequent figures of speech. Both literary devices abound in the ST, especially when characters are repeatedly compared with animals (e.g. Lombard with a predator and $\mathrm{Mr}$ Wargrave with a tortoise). Instances of metaphors such as the ones in segments 9 and 10 (the island is compared with a world) tend to be omitted in the TT. Similes are occasionally maintained (e.g. segment 11).

\begin{tabular}{ll}
\hline 9 & You lost touch with the world-an island - \\
was a world of its own. A world, perhaps, \\
from which you might never return. [...]
\end{tabular}

Table 3

The ST is also characterised by the use of implied metaphors in the plot, such as the ten little figures and the ten soldier boys in the nursery rhyme, which represent the ten guests. Such metaphors are central to the plot of the novel and are usually maintained, but may require a certain degree of explicitation or paraphrase. This is the case of the example in Table 4. In the ST, the record that accuses the guests is entitled Swan Song. The name of 
the record in the TT, The Last Goodbye, manages to preserve its metaphorical meaning despite losing the idiomatic character of the ST expression.

\begin{tabular}{l}
\hline 12 Rogers cried: 'It's the truth, sir. I swear to 'It's true, sir! Honestly! I thought it was a piece \\
God it's the truth. I didn't know what it \\
was-not for a moment' It had a name on \\
it-I the Last It had the name of the music on it - \\
[...] 'Quite right, Sir. It was entitled Swan \\
Song... \\
\hline
\end{tabular}

Table 4

\subsubsection{Non-standard language}

Archaisms

An archaism is as an antiquated word or expression that is no longer in use. Considering the original novel was first published in 1939, there is a sizeable number of archaisms in the ST, none of which are transferred into the TT (e.g. 'games mistress' in segment 13, which is conveyed as 'sports teacher').

13 'Being a games mistress in a third-class Her job as a sports teacher was hard work and school isn't much of a catch... If only I she would like to work in a better school. could get a job at some decent school.

Table 5

The ST also contains a fragment from the King James Version of the Bible, a translation from the $17^{\text {th }}$ century that uses an archaic form of the verb 'execute', which is naturally omitted in the TT (segment 14).

'The heathen are sunk down in the pit that
they made: in the net which they hid is pay for their crimes...
their own foot taken. The Lord is known
by the judgment which he executeth: the
wicked is snared in the work of his own
hands. The wicked shall be turned into
hell.'

Table 6

There is a particular type of archaism that is repeatedly used throughout the ST segments in the corpus: the word 'queer', which in the original context of the novel had the meaning of 'strange' or 'unusual'. In the TT, it has been consistently translated as 'strange'.

\begin{tabular}{lll}
\hline 15 & $\begin{array}{l}\text { Queer business when you came to think } \\
\text { of it }- \text { the whole thing was queer - very } \\
\text { queer... }\end{array}$ & Strange - very strange. \\
\hline 16 & $\begin{array}{l}\text { Queer light eyes that shifted the whole } \\
\text { time from place to place. }\end{array}$ & Her strange, light eyes moved all the time. \\
\hline 17 & $\begin{array}{l}\text { Yes, the guests were queer too. An oddly } \\
\text { assorted party. }\end{array}$ & They were a strange group too. \\
\hline
\end{tabular}

Table 7

Colloquialisms 
The term 'colloquialism' refers to informal words or phrases. There are some instances of colloquial idioms and archaisms, such as the expressions 'by Jove' and 'my foot'. In the TT, informal language is systematically avoided, as shown in Table 8.

\begin{tabular}{lll}
\hline 18 & $\begin{array}{l}\text { By Jove, it had been a near thing } \\
\text { though... }\end{array}$ & - \\
\hline 19 & $\begin{array}{l}\text { Blore said bitterly: 'Mrs Owen's jewels. 'Yes, Mrs Owen's paintings... Mrs Owen! I } \\
\text { Mrs Owen my foot! I don't believe } \\
\text { there's any such person.' }\end{array}$ \\
\hline 20 & '-One or two of your old cronies are \\
& $\begin{array}{l}\text { coming-would like to have a talk over old } \\
\text { times.' }\end{array}$ & You can talk about the past... \\
\hline 21 & $\begin{array}{l}\text { The judge said: 'Marston?' Anthony said: } \\
\text { 'Got a wire. From a pal of mine. Badger }\end{array}$ & 'Marston?' He was there because of a letter \\
& $\begin{array}{l}\text { Berkeley. Surprised me an old friend, now living in Norway. } \\
\text { because I had an idea the old horse had } \\
\text { gone to Norway. }\end{array}$ \\
\hline
\end{tabular}

Table 8

Furthermore, the ST contains a number of colloquialisms typically used to render spoken English contractions, which are omitted in the TT. The examples include ' 'tis' for 'it is' and 'd'yer' for 'do you'.

\begin{tabular}{lll}
\hline 22 & $\begin{array}{l}\text { Sometimes 'tis cut off for a week or } \\
\text { more.' }\end{array}$ & $\begin{array}{l}\text { 'Sometimes nobody can leave the island for a } \\
\text { week or more.' }\end{array}$ \\
\hline 23 & $\begin{array}{l}\text { [...] General Macarthur said: 'You've } \\
\text { never seen him? What d'yer mean?' }\end{array}$ \\
\hline
\end{tabular}

Table 9

\section{Dialect}

The ST contains two references to a dialectal variety of English typically spoken in the geographical setting of the novel: the Devon dialect, or, as Christie prefers to describe it, 'Devon voice', spoken by the taxi driver and by Fred Narracott. These references, which in the ST have the potential of conjuring up a particular accent for many native speakers of English, are fully omitted in the TT, since they mean nothing to the intended readership.

\begin{tabular}{ll}
\hline 24 & 'You'm for Soldier Island, maybe?' he 'Are you for Soldier Island?' he asked. \\
& asked in a soft Devon voice. \\
\hline 25 & $\begin{array}{l}\text { His rolling gait proclaimed him a man of - } \\
\text { the sea. He had a weather-beaten face and }\end{array}$ \\
dark eyes with a slightly evasive \\
expression. He spoke in his soft Devon \\
voice.
\end{tabular}

Table 10

\section{Unusual expressions}

Unusual expressions in the ST may pose comprehension issues for English learners and are often neutralised in the TT. This is the case of segment 26, in which Fred Narracott uses the pronoun 'she' to refer to his boat in the ST. This might be due to the conventional attribution of the feminine gender to boats, which may be unknown for English learners. As a result, 'she' is not kept in the TT, where the standard pronoun 'it' is preferred. 


26 'She'd take double the number, sir. 'It can take twice as many,' replied the boatman.

\subsection{Structural level}

This level encompasses translation shifts affecting structural, grammatical, or syntactical aspects of language. In the TT, these shifts may follow the grammar progression of the five levels of the series Pearson English Active Readers. For instance, English learners at this level may not be familiar with the past perfect tense or with the second conditional. In the segments below, these structures have been avoided in the TT and replaced with sentences in the simple past, a tense that is most likely covered at this level.

\begin{tabular}{lll}
\hline 27 & And then the letter had come. & $\begin{array}{l}\text { The letter came from a woman called Una } \\
\text { Nancy Owen. }\end{array}$ \\
\hline 28 & $\begin{array}{l}\text { If the party had been all like him... he'd } \\
\text { understand it... }\end{array}$ & But why weren't the others like him? \\
\hline
\end{tabular}

Table 12

\subsubsection{Figures of speech}

\section{Anaphora}

Attention to anaphora is strongly encouraged by publishers such as Heinemann, who recommends repeating the antecedent "when reference is across the boundary of a long sentence or several sentences" (Simensen, 1987, p. 53). In the TT, this strategy is adopted in segments such as the ones below, where Hearn explicitly states the antecedents (which have been underlined for emphasis) in place of the ST utterances 'he' and 'the three of them' (marked in bold for emphasis).

\begin{tabular}{lll}
\hline 29 & He'd cut out drink altogether. & Dr Armstrong never drank now. \\
\hline 30 & $\begin{array}{l}\text { The three of them got into the waiting } \\
\text { taxi. }\end{array}$ & $\begin{array}{l}\text { Vera, Lombard and General Macarthur got into } \\
\text { the waiting taxi. }\end{array}$ \\
\hline
\end{tabular}

Table 13

\section{Cataphora}

Cataphora (or forward referencing) is listed as one of the figures of speech that graded reader authors should be careful not to overuse (Waring, 2003, p. 10). However, as demonstrated in the examples below, in which postcedents are underlined and pronouns and noun phrases are shown in bold for emphasis, cataphora does not seem to be a comprehension issue at this level. In segments 34-35, the ST phrase 'a young man' is transferred into the TT as 'the young driver', and the postcedent to which it refers (Anthony Marston) is preserved.

\begin{tabular}{|c|c|c|}
\hline 31 & $\begin{array}{l}\text { At the wheel sat a young man, his hair } \\
\text { blown back by the wind. In the blaze of } \\
\text { the evening light he looked, not a man, } \\
\text { but a young God, a Hero God out of some } \\
\text { Northern Saga. }\end{array}$ & $\begin{array}{l}\text { In the colours of the evening light, the young } \\
\text { driver also looked too perfect, too wonderful to } \\
\text { be an ordinary man. }\end{array}$ \\
\hline 32 & $\begin{array}{l}\text { It was a fantastic moment. In it, Anthony } \\
\text { Marston seemed to be something more } \\
\text { than mortal. }\end{array}$ & $\begin{array}{l}\text { There was, it seemed, nothing ordinary about } \\
\text { Anthony Marston. }\end{array}$ \\
\hline
\end{tabular}

Table 14 
In segment 33, cataphora is used as a strategy to introduce the physical characteristics of Mr Rogers, although this figure of speech is not present in the ST.

\begin{tabular}{|c|c|c|}
\hline 33 & $\begin{array}{l}\text { In the open doorway of the house a } \\
\text { correct butler was awaiting them, and } \\
\text { something about his gravity reassured } \\
\text { them. [...] He was a tall lank man, grey- } \\
\text { haired and very respectable. [...] }\end{array}$ & $\begin{array}{l}\text { At the door of the house a tall, thin, grey- } \\
\text { haired man was waiting for them, - the } \\
\text { manservant, Mr Rogers. }\end{array}$ \\
\hline
\end{tabular}

Table 15

Exophora

Exophora occurs when elements that are not in the text are referenced, i.e. when there is no antecedent or postcedent in the text. For instance, in segment 34, 'drowned' refers to Cyril, but the name of the character is not directly mentioned.

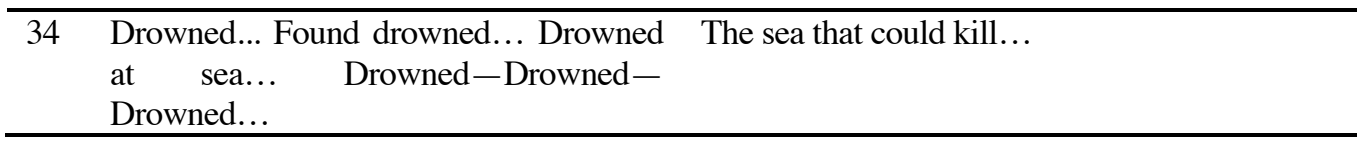

Table 16

Generally, the TT avoids exophora by directly stating the referent, except for those cases in which the reference is deliberately ambiguous, a usual technique in crime fiction. For instance, in segment 35, the pronoun 'it' ('this' in the TT) has got an unclear referent, which may arouse suspicion in the readership towards Anthony Marston.

35 Very few thoughts passed through his I'm really going to do this, am I? he thought. head. Anthony was a creature of But Anthony spent little time thinking. He was sensation - and of action. He thought to a man of action. himself: 'Must go through with it, I suppose,' and thereafter dismissed everything from his mind.

Table 17

\subsubsection{Elliptical and difficult constructions}

\section{Ellipsis}

Ellipsis involves the deletion of elements such as subjects, relative pronouns, the word 'that' and punctuation in clauses. The examples displayed in Table 18 demonstrate that only some of the types of ellipsis listed by Simensen (1985), such as the deletion of subjects in coordinate clauses or the omission of 'that' after 'think', are deemed acceptable in the TT (in bold for emphasis).

\begin{tabular}{|c|c|c|}
\hline 36 & $\begin{array}{l}\text { She went and sat again by the window } \\
\text { looking out to sea. }\end{array}$ & She sat by the window and looked at the sea. \\
\hline 37 & $\begin{array}{l}\text { [...] 'No host and hostess. Very curious } \\
\text { state of affairs. Don't understand this } \\
\text { place.' }\end{array}$ & $\begin{array}{l}\text { 'The Owens aren't here. Very strange. I don't } \\
\text { understand this place.' }\end{array}$ \\
\hline 38 & $\begin{array}{l}\text { [...] I took the name to be either Ogden or } \\
\text { Oliver. I am acquainted with a Mrs Oliver } \\
\text { and also with a Miss Ogden. I am quite } \\
\text { certain that I have never met, or become }\end{array}$ & $\begin{array}{l}{[\ldots] \text { It seemed to be from a woman called }} \\
\text { Ogden or Oliver. I thought I knew her. I'm } \\
\text { sure that I don't know a Mr or Mrs Owen.' }\end{array}$ \\
\hline
\end{tabular}




\begin{tabular}{lll}
\hline & friendly with, anyone of the name of \\
& Owen.' \\
\hline 39 & 'Any reason given'?' & 'Was any reason given?' asked the judge. \\
\hline
\end{tabular}

Table 18

\section{Difficult constructions}

Difficult constructions may include lengthy noun clauses, subclauses and relative clauses as subjects, contractions, inversions, indirect speech and participle phrases. Admittedly, the degree of difficulty of such constructions depends on the level of the graded reader. In the case of the TT, contractions and indirect speech are not considered an obstacle for comprehension, as it can be inferred from the two examples below.

\begin{tabular}{lll}
\hline 40 & $\begin{array}{l}\text { Emily Brent said: 'That's a very small } \\
\text { boat.' }\end{array}$ & 'That's a very small boat,' said Emily Brent. \\
\hline 41 & $\begin{array}{l}\text { Lombard said to Rogers: 'Get some } \\
\text { brandy.' }\end{array}$ & Lombard told Rogers to get her a strong drink. \\
\hline
\end{tabular}

Table 19

On the other hand, lengthy noun clauses and relative clauses as subjects tend to be avoided in the TT, where simple sentences are much preferred.

\begin{tabular}{lllll}
\hline 42 & $\begin{array}{l}\text { The loud drawn-out scream of an } \\
\text { approaching train was heard. }\end{array}$ & Then they heard a loud noise. \\
\hline
\end{tabular}

Table 20

As for inversions, the TT tends to build clauses that conform to the SVO word order, the most typical in English, and to consistently revert the usual order of the ST elements in direct speech by always stating the utterance before the speaker.

\begin{tabular}{lll}
\hline 43 & $\begin{array}{l}\text { From his pocket Mr Justice Wargrave } \\
\text { drew out a letter. }\end{array}$ & $\begin{array}{l}\text { Mr Justice Wargrave took a letter out of his } \\
\text { pocket. }\end{array}$ \\
\hline 44 & He said: 'Isn't that rather unusual?' & 'Isn't that unusual?' Lombard asked. \\
\hline
\end{tabular}

Table 21

\subsection{Information level}

Shifts occurring at the information level include omissions, additions and shifts related to chapter segmentation.

\subsubsection{Omissions}

Omission of full sentences and even paragraphs from the ST is the most commonly used technique in abridgement. Abridged graded readers tend to be considerably less lengthy than their original versions, which makes them more 'digestible'. In the TT, the word count has been cut down by circa $65 \%$, from 52,656 words to only 18,683. Such a vast abridgement is achieved by consistently omitting 'marginal', 'peripheral' or 'irrelevant' information throughout the novel, including secondary characters (e.g. Emily Brent's father, a Colonel of the old school, in segment 45) and background descriptions (e.g. the scenery in Devon on the way to the island, in segment 46; or the decoration in Vera's room, which uses plenty of adjectives, in segment 47). 


\section{Table 22}

\begin{tabular}{ll}
\hline 45 & $\begin{array}{l}\text { Her father, a Colonel of the old school, Politeness was important too. } \\
\text { had been particular about deportment. }\end{array}$ \\
\hline 46 & $\begin{array}{l}\text { They drove through the sleepy streets of } \\
\text { little Oakbridge and continued about a } \\
\text { mile on the main Plymouth road. Then } \\
\text { arrived at the small village of Sticklehaven. }\end{array}$ \\
& lhey plunged into a maze of cross country \\
& lanes, steep, green and narrow. \\
\hline 47 & [...] A perfect bedroom decorated - \\
throughout in the modem style. Off white \\
rugs on the gleaming parquet floor- \\
faintly tinted walls - a long mirror \\
surrounded by lights.
\end{tabular}

\section{Controversial issues}

The use of omission as a translation strategy is never exempt of controversy, and omission in graded readers could not be an exception. Since there is no easy way to identify what exactly is 'necessary' in a plot, omission can be used by publishers as a means of censorship and ideological manipulation. Hill reports that "for the most part the treatment of potentially controversial themes such as religion, politics, sexual behaviour, violence and the occult conforms to Western notions of what is appropriate for secondary school students" (1992, p. 10). This kind of purification has been systematically deployed in the translation of children's literature. In the last few decades, however, there has been a shift in the criteria for censorship: while sex, vulgar expressions and liberal views are no longer perceived as problematic, passages that are considered racist or socio-politically incorrect are likely to be censored (Fernández López, 2000, p. 30).

The two main controversial issues that have been identified in the corpus are anti-Semitic and sexist slurs, something to be expected considering the year of publication of the novel (1939). Christie's endorsement to these views is not entirely clear: it could be argued that she was solely giving her characters the sort of beliefs that were typical of her time, but she could also be communicating her own opinions.

Anti-Semitic remarks in the ST include the stereotypical characterisation of Mr Morris (see segment 48) and the derogative use of the words 'little' and 'thick' in front of 'Jew' and 'Semitic lips' respectively (see segments 49 and 50). In the TT, all references to the 'Jewishness' of Mr Morris are thoroughly omitted.

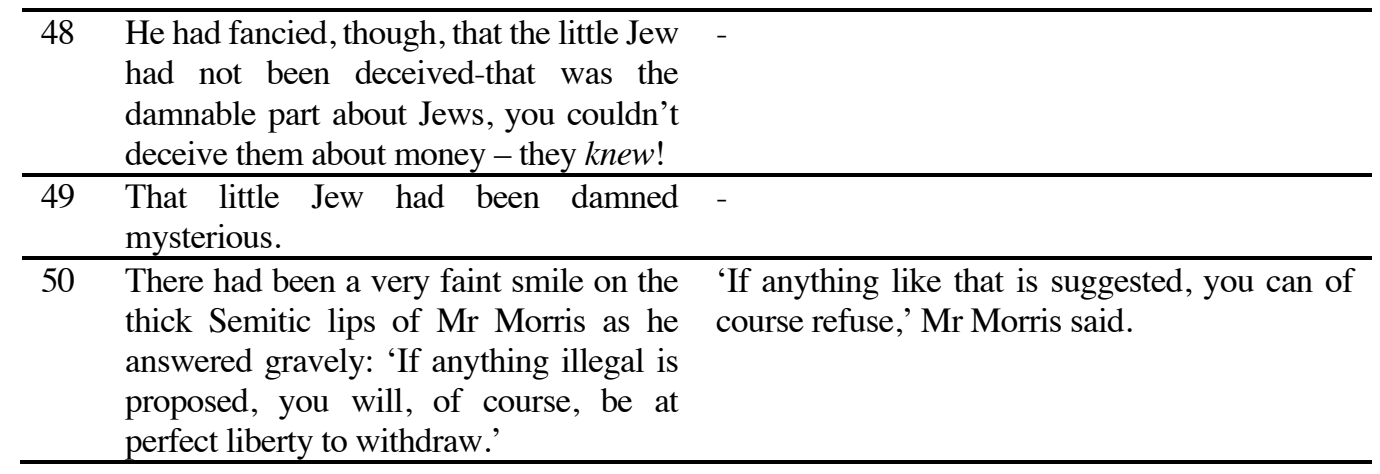

Table 23

As for the sexist remarks, some of them are directly addressed to the female characters in the novel, Vera Claythorne and Miss Emily Brent (see segments 51 and 52). However, segments 53 and 54 depict the general 
sexist views of Dr Armstrong and Mr Wargrave, who describe women as hypochondriac, easily deceivable and 'undependable'.

\begin{tabular}{lll}
\hline 51 & $\begin{array}{l}\text { He didn't care for the girl, cold-blooded } \\
\text { young hussy. }\end{array}$ \\
\hline 52 & $\begin{array}{l}\text { One old maid-the sour kind-he knew } \\
\text { them well enough. She was a tartar he }\end{array}$ & $\begin{array}{l}\text { The old woman - unmarried and not very } \\
\text { pleasant. }\end{array}$ \\
& could bet. \\
\hline 53 & $\begin{array}{l}\text { Her nerves - Nerves! The doctor's - - } \\
\text { eyebrows went up. These women and } \\
\text { their nerves! Well, it was good for }\end{array}$ \\
business, after all. Half the women who \\
consulted him had nothing the matter \\
with them but boredom, but they \\
wouldn't thank you for telling them so! \\
[...] \\
\hline 54 & Undependable like all women. \\
\hline
\end{tabular}

Table 24

Arguably, it could be interesting for language learners to be exposed to controversial or offensive items, such as the anti-Semitic and sexist language above. According to Ersland, who studied the norms and laws in transatlantic adaptation, "in editing out problematic subjects, one runs the risk of overprotecting one's audience, whether of a younger or older age. Sometimes we need to be confronted with that which may, or may not, make us uncomfortable" (2014, p. 90). Her opinion is in line with that of scholars like Oittinen, who claimed that "very often we adults censor and sanitize children's stories for our own purposes" (2000, p. 50).

\subsubsection{Additions}

Additions in the TT may include words and sentences directly incorporated into the text, footnotes, illustrations, introductions, lists of characters and wrap-up activities. Their two main aims are to improve comprehensibility and to address the cultural and background differences between the readership of the ST and that of the TT.

The first type of addition, namely the inclusion of textual contents in the text that cannot be traced back to the ST, is rare in the corpus. An example of addition embedded within the TT is segment 55, which could be interpreted as an explicitation of the meaning of the judge's utterance (i.e. they are too many people for such a small boat).

\begin{tabular}{lll}
\hline 55 & $\begin{array}{l}\text { Mr Justice Wargrave said sharply: 'There } \\
\text { are a good many of us.' }\end{array}$ & $\begin{array}{l}\text { 'There are a lot of us,' added the judge. 'Are you } \\
\text { sure it can carry us all?' }\end{array}$ \\
\hline
\end{tabular}

Table 25

\section{Footnotes}

The use of footnotes in graded readers is not as discouraged as in interlingual translations, where translator's notes has been perceived as intrusive by some scholars (Albakry, 2004, p. 4). In the TT, footnotes provide either cultural information (as in segment 56, where the meaning of the title 'Justice' is explained) or the definition of a difficult word that has not been 'translated', e.g. some of the words in the nursery rhyme, which are instrumental to the plot. Definitions are followed by an indicator of the word type (e.g. '(n)' for nouns) and a phonetic transcription of the word, which has not been included in the corpus. 


\begin{tabular}{|c|c|c|}
\hline 56 & $\begin{array}{l}\text { In the corner of a first-class smoking } \\
\text { carriage, Mr Justice Wargrave, lately } \\
\text { retired from the bench, puffed at a cigar } \\
\text { and ran an interested eye through the } \\
\text { political news in The Times. He laid the } \\
\text { paper down and glanced out of the } \\
\text { window. }\end{array}$ & $\begin{array}{l}\text { Mr Justice Wargrave* looked out of the window } \\
\text { of the train. } \\
\text { *Mr Justice Wargrave's title, since he became a } \\
\text { judge. }\end{array}$ \\
\hline 57 & $\begin{array}{l}\text { Three little soldier boys walking in the } \\
\text { Zoo; A big bear hugged one and then } \\
\text { there were Two. }\end{array}$ & $\begin{array}{l}\text { Three little soldier boys were walking in the } \\
\text { zoo. An animal killed one and then there were } \\
\text { too. } \\
\text { zoo (n) a place where wild animals are kept. } \\
\text { People visit zoos to see the animals. }\end{array}$ \\
\hline
\end{tabular}

Table 26

Illustrations

In the TT, full-colour illustrations are used to graphically represent some of the contents of the story. Although these illustrations do not always provide a direct comprehension support for difficult fragments of the story, they help to 'digest' the meaning of the TT.

Titles and introductions

The TT includes titles and introductory sentences to every chapter that do not appear in the ST. For instance, episodes 1 to 3 are titled Journey to Soldier Island, Ten Little Soldier Boys, and The Voice respectively. The introductory sentences are drawn from their own chapter and give a foretaste of the forthcoming events.

\section{Wrap-up activities}

Pre-reading, while-reading and post-reading activities are distributed throughout the TT. The purpose of prereading activities is to set up the historical and geographical context of the novel (when does the story happen, what is it about, where are the characters...). While-reading activities appear every two chapters and are used to reinforce the learning of vocabulary and grammar structures (e.g. the passive voice) and to help the readership to digest the story. For instance, the activities between Chapter 2 and Chapter 3 provide a list of characters and encourage learners to guess what will happen next. Post-reading activities are meant as a starting point for oral and written production.

\subsubsection{Chapter segmentation}

The ST comprises sixteen chapters, an epilogue and a postscript. The TT, however, only has twelve chapters, the last of which comprises the epilogue and the postscript. As stated in the literature review, chapters in graded readers are kept short in order to prevent an information overload in the readership (Hedge, 1985, p. 15).

\section{Discussion}

Abridgement of literary works is a norm-governed activity in which the author is engaged in a decision-making process, just like in any other process of translation. However, one of the main differences with interlingual translation is the pivotal role of publishers in the dictation of translation norms through grading schemes and 
guidelines for abridgement. An illustrative example of a socio-cultural norm enforced by publishers is the avoidance of controversial issues in Western societies. In other words, when publishers determine which topics should be avoided or approached carefully in their graded readers, they are dictating translation norms.

When comparing the checklist used for analysis in this article with the operational norms proposed by Toury, a certain parallelism can be detected. These norms, which can be divided into textual-linguistic (lexical items and stylistic features) and matricial norms (fullness, distribution and segmentation of the text) roughly correspond to the levels of control under which the analysis has been conducted, i.e. lexical and syntactical (language level) and information level. On the basis of the findings obtained from the shifts at the language level, the following textual linguistic norms can be identified:

- Figurative language (i.e. idioms, metaphors and similes) is liable to be preserved in the TT, but it should not be overused. Non-standard language (i.e. archaisms, dialect, colloquialisms and unusual expressions) should always be avoided.

- Anaphoric pronouns should be replaced by their antecedents at the author's discretion. The use of cataphora is allowed. Exophoric references should be made explicit, except when the ST is deliberately ambiguous.

- Structural constructions that may be considered difficult for English learners (e.g. contractions, indirect speech and ellipsis) should be avoided when they surpass the assumed level of the readership.

Likewise, the matricial norms underlying the process of abridgement can be reconstructed by means of the information shifts previously analysed.

- The graded reader author should cut down all the secondary information that she or he considers irrelevant, to the point that the size of the TT may be reduced by more than half. Controversial issues (e.g. anti-Semitism and sexism) should be avoided.

- The addition of footnotes, illustrations, introductions and wrap-up activities is allowed and fulfil essential functions in the TT.

- Chapter segmentation in the TT does not need to correspond to that of the ST (i.e. there should be fewer chapters).

In general, the norms listed above corroborate the findings of research on graded reader control conducted by Hedge (1985), Simensen (1987) and Waring (2003). There are only two contradictions: cataphoric references do not seemingly require to be treated with care in the TT, and some of the so-called 'difficult constructions' in the theoretical framework (e.g. contractions and indirect speech) are allowed and frequently used throughout the TT.

The contextualisation previously undertaken opens the way for the identification of the preliminary norms that operated prior to the process of abridgement of the ST. The first preliminary norm proposed by Toury is the translation policy that determines the selection of texts, authors and languages for translation. Naturally, publishers have an interest in abridging best-selling classics. Classic literary works such as And Then There Were None are easy to promote (the novel is considered a crime fiction masterpiece and it is one of the best-selling titles of all time) and are likely to be chosen by language learners as a part of their extensive reading experience, since they are universally known.

Furthermore, if the ST was written by an influential author such as Agatha Christie (the most-translated and best-selling individual writer of all time), it is likely to be chosen for abridgement regardless of its individual fame. This norm is supported by the fact that over 20 'Christies' have been turned into graded readers by two different publishers. The last factor behind the choice for abridgement of this ST is its original language. English 
is the most widely spoken second language in the world, and the market of graded readers for EFL learners is by far the largest. As for Toury's second preliminary norm, which concerns the directness of translation, the existence of an intermediate language in any process of abridgement is highly unlikely.

The last of Toury's norms is the initial norm, i.e. the general choice towards the norms of the source (adequate translation) or the target culture (acceptable translation). Based on Schmid's concept of 'culture' as a system of concepts that enables successful interaction amongst people (2008, p. 44), the target culture in the context of abridgement can be defined as the ensemble of concepts held by language learners about their second or foreign language and its culture(s). Just like native speakers, learners undergo a process of language and culture acquisition, which gradually allows them to read in their foreign or second language. In the case of the TT, learners at this level of language and cultural proficiency are not expected to know that 'Justice' is a title held by a judge or that a red herring is 'something that takes your thoughts away from something important'. In general terms, the considerable number of shifts in the TT points towards an acceptable translation, since the text seems to conform to the norms in the target culture, a strategy that is coherent with the target readership of the TT (pre-intermediate learners).

It is important to note that the validity of the norms above is restricted to the research corpus of this article, and their applicability to all instances of abridgement should not be assumed. A larger corpus-based study would be necessary in order to extrapolate the results of this analysis in a general way. This limitation makes it difficult to test the two tentative laws formulated by Toury. However, it can be argued that their application to the process of abridgement depends on the degree of simplification or control applied in the text. Thus, in graded readers for beginner and pre-intermediate learners, where there is a large gap between the assumed language proficiency and cultural knowledge of the ST and TT readership, there might be a tendency to ignore textual features in the ST and choose more habitual linguistic options in the TT (law of growing standardisation). On the other hand, in graded readers for intermediate and advanced learners, where this gap is considerably narrower, ST features will be more likely to be directly transferred to the TT (law of interference). Another factor which may influence the application of these laws is the literary merit of the ST within its culture. For instance, in the abridgement of poetry, whose prestige has been traditionally superior to that of genres like crime fiction or children's literature, the law of interference might tend to prevail over the law of growing standardisation.

\section{Conclusions}

This article has sought to discover translational regularities in the process of abridgement of the novel And Then There Were None for English learners. The approach has been purely descriptive, based on the examination of the three first chapters of the original novel (the ST) and of the graded reader (the TT), which have formed the research corpus of this study.

The results of the analysis have revealed the presence of operational and preliminary norms in the abridgement of the ST, which have mostly supported the existing research on the process of simplification or control by Hedge (1985), Simensen (1987) and Waring (2003). In particular, lexical and structural shifts have been discovered to correspond to textual-linguistic norms, whereas shifts occurring at the information level have been found to be an indicator of matricial norms. The text has been revealed to be an acceptable translation, in which the law of growing standardisation prevails over the law of interference. There have been some findings in regard 
to the laws governing the production of the TT as well, but the research corpus ought to be extended in order to reach more solid conclusions.

In this regard, the methodology, based on a check-list of features distributed across the three levels of control in graded readers, has been proven successful and may serve as a valid basis for similar analyses. However, its limitations need to be considered as well. For instance, the process of segment alignment has been more asymmetrical and less straightforward than expected. This is due to the enormous number of shifts (especially omissions) that occur in abridgement as opposed to interlingual translation. It would be interesting to further examine the reasons behind these omissions, especially the ones regarding controversial issues, in order to assess the role of censorship and ideological manipulation in the intralingual translation of literature.

Furthermore, the categories created for the analysis do not cover all the aspects that could yield information about the underlying norms and laws in abridgement. Due to the limited scope of this article, it was decided to restrict the focus to the shifts corresponding to the elements listed in the theoretical framework, but many other research paths remain open. For instance, an in-depth study of paratextual elements (e.g. cover, synopsis, formatting, and so on) could shed light on the nature of abridgements and the reasons underpinning the shifts occurring in the text.

Despite these methodological challenges, this study has achieved to describe the abridgement of a literary work for language learning purposes as an instance of intralingual translation. It can therefore be concluded that it has contributed to bridging the current gap in translation research.

\section{About the author}

Manuel Moreno Tovar holds a bachelor's degree in Translation and Interpreting (English and German) from the University of Granada. In 2012 he received an Erasmus scholarship to study in Ghent (Belgium) for an academic year. He has also participated in international mobility programmes at the University of Seoul (South Korea) and Tohoku University (Japan). For his postgraduate studies, he opted for a master's degree in Translating at Heriot-Watt University (Scotland). Upon graduation, he was selected for a traineeship at the Directorate-General for Translation in Brussels. Then he returned to Granada, where he was employed as a Dutch lecturer and a technical assistant for research at the University of Granada. He is currently pursuing a $\mathrm{PhD}$ programme at the University of Tartu (Estonia), where he is also involved in LGBT+ activism and the fight against the climate crisis. His project focuses on intralingual translation for language learners from a gender-sensitive approach.

\section{Acknowledgements}

Thanks to my parents and sister for remaining a constant in my life, and to Mercedes Díaz Dueñas, Fernando García de la Banda and Ignacio Garrido Rodríguez for assisting me in getting where I am now. 


\section{References}

Primary data

Christie, A. (1939/2015). And Then There Were None. London: Harper Collins.

Christie, A.; Hearn, I. (2011). And Then There Were None. Harlow: Pearson Education.

Secondary data

Albakry, M. (2004). 'Linguistic and Cultural Issues in Literary Translation'. Translation Journal 8(3). <http://translationjournal.net/journal/29liter.htm>. [02/05/2019].

Baker, M. (2009). Introduction to the first edition. In Baker, M. (Ed.), Routledge Encyclopedia of Translation Studies (pp. 14-19). London: Routledge.

Bassett. J. (2011). A series editor's view (1). In Day, R. et al. (Eds.), Bringing Extensive Reading into the Classroom (pp. 22-32). New York: Oxford University Press.

Ersland, A. (2014). IS CHANGE NECESSARY? A study of norms and translation universals in intralingual translation. Unpublished MA thesis. University of Bergen. <http://bora.uib.no/bitstream/handle/1956/7967/119571513.pdf;sequence=1>. [02/05/2019].

Fernández López, M. (2000). ‘Translation Studies in Contemporary Children’s Literature: A Comparison of Intercultural Ideological Factors'. Children's literature Association Quarterly, 25(1), 29-37.

Hedge, T. (1985). Using Readers in Language Teaching. London: Macmillan.

Hill, D. R. (1992). Guide to Organising Programmes of Extensive Reading. <http://er-central.com/wp-content/uploads/EPER-Guide1992.pdf>. [02/05/2019].

Jakobson, R. (2004). On Linguistic Aspects of Translation. In Venuti, L. (Ed.), The Translation Studies Reader (pp. 180-192). New York \& London: Routledge.

Leow, R. P. (2007). 'Review of Resources: Simplification and Second Language Acquisition'. World Englishes, 16(2), $291-296$.

Munday, J. (2008). Introducing Translation Studies: theories and applications. 2nd edn. London: Routledge.

Pearson English Readers Catalogue (2019). <https://online.flippingbook.com/view/176977> [02/05/2019].

Schmid, B. (2008). A duck in rabbit's clothing: integrating intralingual translation. In Kaiser-Cooke, M. (Ed.), Das Entenprinzip: translation aus neuen Perspektiven (pp. 19-80). Bern: Peter Lang.

Simensen, A. M. (1987). ‘Adapted Readers: How are they Adapted?'. Reading in a Foreign Language 4(1), 41-57.

The Extensive Reading Foundation (2011). The Extensive Reading Foundation's Guide to Extensive Reading. $<$ http://erfoundation.org/guide/ERF Guide.pdf $>$ [02/05/2019].

Toury, G. (2012). Descriptive Translation Studies - and beyond. Revised edition. Amsterdam \& Philadelphia: John Benjamins.

Oittinen, R. (2000). Translating for Children. New York: Garland.

Waring, R. (2003). Writing a Graded Reader. <www.robwaring.org/papers/Writing graded reader.doc> [02/05/2019].

Zethsen, K. K. (2007). 'Beyond Translation Proper: Extending the field of translation studies'. TTR : Traduction, Terminologie, Rédaction 20(1), 281-308.

Zethsen, K. K. (2009). 'Intralingual translation: An attempt at description'. Meta 54(4), 795-812. 